\title{
AIR POLLUTANTS, EMISSIONS AND CARBON FOOTPRINT AT CITY LEVEL: THE CLAIRCITY PROJECT
}

\author{
CARLO TROZZI, ENZO PISCITELLO \& RITA VACCARO \\ Techne Consulting Srl, Roma, Italy
}

\begin{abstract}
The paper reports about integrated quantification of air pollutants emissions and carbon footprint in the frame of Horizon 2020 Project ClairCity. ClairCity is a four year project (2016-2020) working directly with citizens and local authorities in six countries around Europe. In the project sixteen partner organisations are involved. From the adoption of the Kyoto Protocol to the United Nations Framework Convention on Climate Change, great attention has been devoted to reducing carbon dioxide and other greenhouse gases emissions at the international level and specific initiatives at city level have been launched. At the same time despite continued efforts to reduce emissions of harmful air pollutants, air pollution remains a worldwide concern, including in large areas of Europe, particularly in cities where the effects on human health are the major concerns. For a long time, policies aimed at reducing greenhouse gases emissions and those aimed at improving air quality have been indifferent to one another if not in contradiction. Inside ClairCity project a complete innovative set of tools for the integrated evaluation of air pollution and carbon footprint at city level was designed and developed. The approach for air pollutants emissions evaluation follow the well developed methodology from EMEP-EEA Task force on emission inventory and projections. The emission inventory is finalized to evaluate pollution to a very detailed activities levels and territorial domains. Emissions evaluation methodology and emission factors are collected and a modelling framework to obtain territorially disaggregated emissions is introduced. For carbon footprint different approaches are followed by the project with reference to the use of conventional emission factors and lyfe cycle emission factors. In the paper methodologies for emission inventory and carbon footprint evaluations are introduced. Bristol and Amsterdam baseline scenario case studies results are reported with reference to emission inventory of industrial, residential and commercial sources and for overal city level carbon footprint. The output of the activities will be the input for air quality, people exposure and health effects modeling,

Keywords: emissions inventory, carbon footprint, life cycle emission factors, cities, Bristol, Amsterdam, air quality models.
\end{abstract}

\section{INTRODUCTION}

ClairCity [1] is a four-year project (2016-2020) developed in the frame of Horizon 2020 [2] working directly with citizens and local authorities in six countries around Europe. There are sixteen partner organisations involved in the project.

Two decades of established emissions inventories and evolving modelling practices across the EU have only taken air quality management and carbon reduction strategies so far. It can be argued that this is because the policy and methodologies used have, for a number of reasons, led us towards attempts to reduce emissions predominantly through technical measures, and away from changing the way our societies and cities operate and function.

ClairCity project apportions air pollution emissions and concentrations, carbon footprints and health outcomes by city citizens' behaviour and day-to-day activities in order to make these challenges relevant to how people chose to live behave and interact within their city environment. ClairCity uses six pilot cities/regions (Amsterdam, NL; Bristol, UK; Aveiro, PT; Liguria, IT; Ljubljana, SI; and Sosnowiec, PO).

A set of tools for the integrated evaluation of air pollutant emissions inventory and carbon footprint at city level are designed and developed in the project. Baseline scenario evaluation 
and future scenarios for simultaneous reduction of air pollutants emission and carbon footprint are produced in the project.

The paper discusses the tools realized for air pollutants emissions evaluation:

- Using existing industrial emissions data (EMEP, E-PRTR, others);

- From small combustion in residential, commercial and institutional sector;

- From transport.

Next the approach followed to evaluate carbon footprint is introduced and discussed. As the project is finalized to produce strategies for the cities, the carbon footprint evaluation is conducted following an emission inventory approach similar to the approach followed in the Covenant of Mayors and using both: "Standard" emission factors (emissions are evaluated using methodologies and emission factors from 2006 IPCC Guidelines for National Greenhouse Gas Inventories and specific activity level) than LCA (Life Cycle Assessment) emission factors, which take into consideration the overall life cycle of the energy carrier. In the standard approach, emissions are reported as $\mathrm{CO}_{2}$ only emissions and $\mathrm{CO}_{2}$ equivalent emissions, including calculation of the emissions of $\mathrm{CH}_{4}$ and $\mathrm{N}_{2} \mathrm{O}$ using the Global Warming Potential (GWP) with 100-year time horizon.

Finally, the results in baseline scenario for first two case studies, relative to Bristol and Amsterdam will be discussed introducing: the domain selected and the level of geographic detail of the evaluations, the methodologies for fuel consumptions evaluation and the results for air pollutants emissions and carbon footprint estimates.

\section{CLAIRCITY PROJECT}

ClairCity [3] apportions air pollution emissions and concentrations, carbon footprints and health outcomes by city citizens' behaviour and day-to-day activities in order to make these challenges relevant to how people chose to live and behave and interact within their city environment.

Through an innovative engagement and quantification toolkit, the project stimulates the public engagement necessary to allow citizens to define a range of future city scenarios for reducing their emissions to be used for supporting and informing the development of bespoke city policy packages out to 2050 .

Using six pilot cities/regions (Amsterdam, NL; Bristol, UK; Aveiro, PT; Liguria, IT; Ljubljana, SI; and Sosnowiec, PO), ClairCity source apportions current emissions/ concentrations and carbon emissions not only by technology but by citizens' activities, behavior and practices.

ClairCity explores and evaluates current local, national and international policy and governance structures to better understand the immediate policy horizon and how that may impact on citizens and their city's future. Then, working with the new methods of source apportionment to combine both baseline citizen and policy evidence, ClairCity uses innovative engagement methods such as Games, an App and Citizen Days to inform and empower citizens to understand the current challenges and then subsequently define their own visions of their city's future based on how their want to live out to 2050. The impact of these citizen-led future city scenarios is analysed, to develop city specific policy packages in which the clean-air, low-carbon, healthy future, as democratically defined by the city citizens, is described and quantified.

The results of the ClairCity process are evaluated to provide policy lessons at city, national and EU levels. Additionally, the toolkit structure is developed for all EU cities with more than 50,000 citizens establishing a basis to roll out the ClairCity process across Europe. 


\section{CLAIRCITY INTEGRATED MODELLING TOOLKIT}

The primary aim of the quantification activities is the integration of several modelling tools (Integrated Modelling Toolkit) to provide a robust scientific basis for the assessment of the impacts of future scenarios, to support policy advice for EU cities and to provide data feeds for the Game and App. Within this task a database is also be developed combining, integrating and data-mining existing databases populated with relevant parameters that determine behaviour, activity, emissions and consequently air quality of a city, initially for six pilot cities and later in a simplified and generic way for all EU cities with 50k inhabitants or more.

The Integrated Modelling Toolkit (Fig. 1) is able to blend the traditional modelling approaches used for the assessment of air quality, carbon footprint, health etc. with the innovative citizen-centered approach coming from the project, in order to build an integrated environment that will provide decision makers with a coherent picture for the assessment of scenarios. The toolkit will also estimate the impact of activities and measures on pollutant emissions and mapping air quality, carbon footprint and health for each pilot city to support a Game and an App.

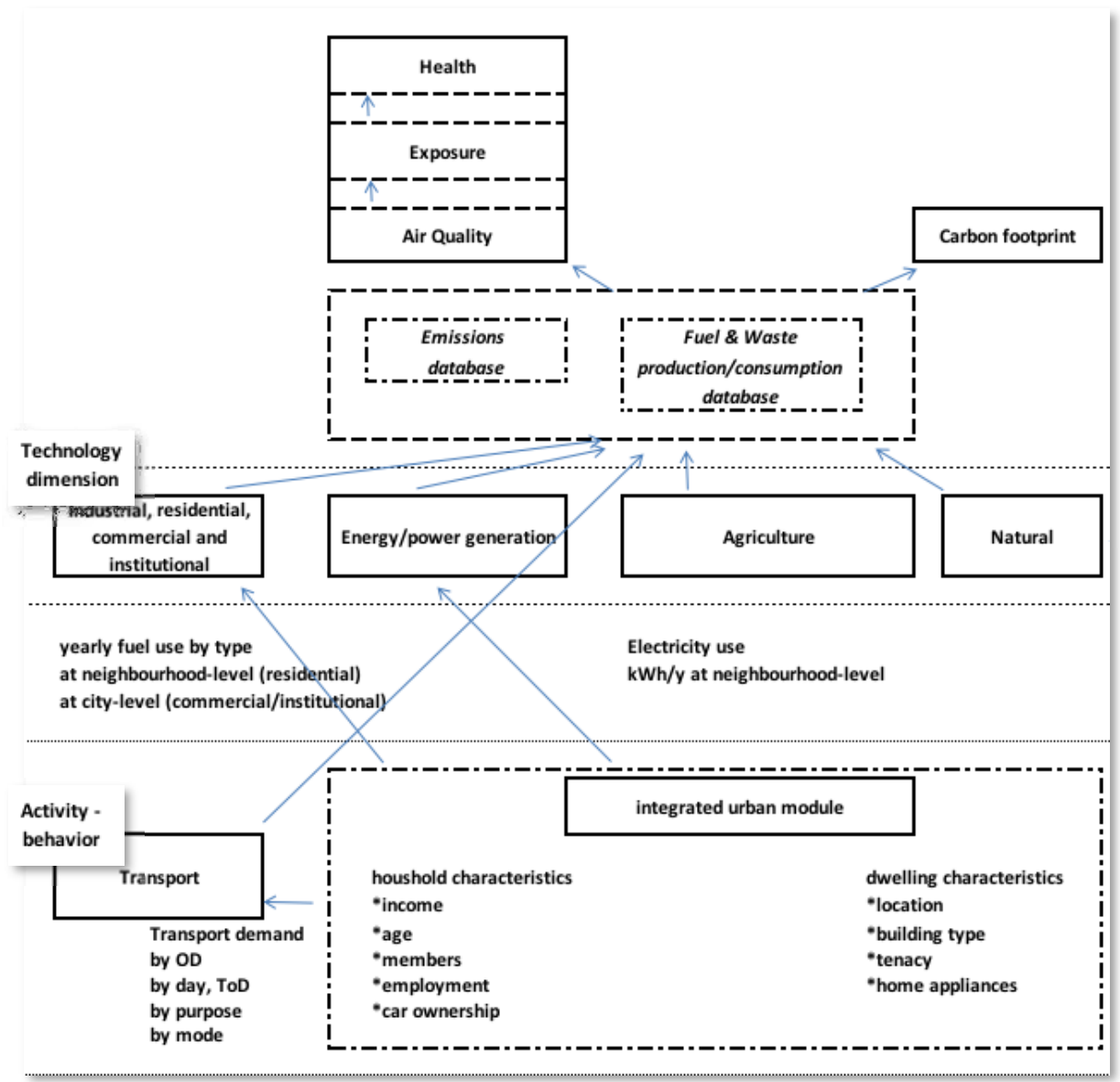

Figure 1: ClairCity Integrated Modelling Toolkit. 
The Integrated Modelling Toolkit as such contains activity modeling, impact modeling, the database feeding these models as well as the tools used in city engagement, the game and app. This toolkit is used in context of this project, but also a generic, simplified toolkit, paving the way for future application of the in other cities.

\section{INTEGRATE AIR POLLUTANTS EMISSIONS AND \\ CARBON FOOTPRINT EVALUATIONS}

Despite continued efforts to reduce emissions of harmful air pollutants, air pollution remains a worldwide concern, including in large areas of Europe [4]. Improving air quality while keeping the climate hospitable is a complex process which requires a thorough understanding of what is causing air pollution and climate change, what can be done to tackle both, and a prioritisation of measures to preserve a life-friendly atmosphere everywhere on Earth. To improve air quality, the European Union has set specific long-term objectives for 2020 through its Thematic Strategy on Air Pollution, which has been reviewed and led to the Clean Air Policy Package. The EU also aims to limit global warming to $2^{\circ} \mathrm{C}$ above preindustrial levels.

From the adoption of the Kyoto Protocol to the United Nations Framework Convention on climate change, great attention has been devoted to reducing carbon dioxide emissions and other greenhouse gases at the international level and specific initiatives at city level have been launched [5]. At the same time despite continued efforts to reduce emissions of harmful air pollutants, air pollution remains a worldwide concern, including in large areas of Europe, particularly in cities where the effects on human health are the major concerns. For a long time, policies aimed at reducing greenhouse gases and those aimed at improving air quality have been indifferent to one another if not in contrast.

Typical examples of this dichotomy are: the past implemented incentive policies for diesel cars that, while they have specific lower $\mathrm{CO}_{2}$ emissions, involve much higher $\mathrm{NO}_{\mathrm{x}}$ and $\mathrm{PM}$ emissions, and the policies of incentive for biomass that, while they have a relative carbon neutrality, involve high PM emissions.

\section{AIR POLLUTANTS EMISSIONS INVENTORY}

In this section the design and development of emission inventory tool is reported with specific focus on Industry Residential/Commercial and Other services module. Other works from the project team report about the transport emissions evaluations and the other topics.

The air pollutants included in the tool are nitrogen oxides $\left(\mathrm{NO}_{\mathrm{x}}\right)$ and suspended particles with diameter less than $10 \mu \mathrm{m}\left(\mathrm{PM}_{10}\right)$.

Emission sources are generally classified as point, area and line sources. Point sources are stationary sources whose emissions exceed some thresholds, fixed depending on the aim of the inventory. In order to compile city/region inventory in ClairCity, stationary emission sources with total annual emissions with at least one pollutant emissions exceeding 100 $\mathrm{Mg} /$ year, are considered as Large Point Sources (LPS).

\subsection{Industrial sources}

For industrial sources emissions, a specific tool has been developed to include all the emissions from the European Pollutant Release and Transfer Register (E-PRTR) [6] facilities and national, regional and local Registers or emissions inventories. Where specific facilities are individuated that don't have known emissions data, ad hoc estimates are obtained using available information and emission factors from EMEP/EEA Guidebook [7]. The emissions have been geographically allocated by coordinate of emission source. Large Point Sources 
have been individuated and reported, source by source, with emissions and characteristics of emissions (gas temperature and volume and stack height).

\subsection{Residential, commercial and institutional sector emission modeling}

The emission modelling tool evaluates emissions at most detailed administrative territorial units level, uses emission factors from EMEP/EEA Guidebook [7], as:

$$
\mathrm{E}=\mathrm{A}_{\mathrm{ij}} \mathrm{F}_{\mathrm{ik}},
$$

where:

- $\mathrm{A}_{\mathrm{ij}}$ is the indicator of the activity $\mathrm{i}$ in the territorial unit $\mathrm{j}$,

- $\mathrm{F}_{\mathrm{ik}}$ is the emission factor of pollutant $\mathrm{k}$ for activity $\mathrm{i}$ (expressed in grams per unit of activity).

For small combustion in residential, commercial and institutional sector emissions have been evaluated using emission factors from EMEP/EEA Guidebook [7] and specific activity level. In Table 1 the fuel combustion air pollutants emission factors used are reported.

The module needs in input, data on fuel consumptions in residential and commercial sectors, detailed by technologies and fuels.

Air Pollutant emissions are evaluated on defined subdomains (for example LSOA for Bristol, buurt for Amsterdam, etc.). When data are available only in aggregate figures (overall domain) or at national level, they are allocated to subdomains using a "proxy" variable available at subdomains level. The data know at domain or national levels are evaluated on subdomains using a lot of proxy variables known at the subdomains level. Proxy variables allow obtaining information on a certain spatial resolution assuming that it is known for larger spatial resolutions.

When data are available at city/region domain, data at subdomain level is evaluated using the following equation:

$$
\mathrm{A}_{\mathrm{i}}=\mathrm{A} * \mathrm{P}_{\mathrm{i}} / \Sigma_{\mathrm{i}} \mathrm{P}_{\mathrm{i}}
$$

where: $A_{i}$ and $P_{i}$ are the values of variable $A$ and proxy variable $P$ in the subdomain $i$, and $A$ is the total of variable $\mathrm{A}$ in the domain.

Table 1: Residential and commercial air pollutant emission factors.

\begin{tabular}{lcc}
\hline Fuel & $\begin{array}{c}\text { Nitrogen oxides } \\
{\left[\mathrm{gNO}_{\mathrm{x}} / \mathrm{GJ}\right]}\end{array}$ & $\begin{array}{c}\text { Particle matter with diameter } \\
\text { less than } 10 \mu \mathrm{m} \\
{\left[\mathrm{gPM}_{10} / \mathrm{GJ}\right]}\end{array}$ \\
\hline Boilers - natural gas & 42 & 0,2 \\
Boilers - LPG & 40 & 2 \\
Boilers - gas/diesel oil & 69 & 1,5 \\
Boilers - wood & 80 & 480 \\
Fireplaces - wood & 50 & 840 \\
Stoves - wood & 50 & 760 \\
Energy efficient fireplaces - wood & 80 & 380 \\
Energy efficient ftoves - wood & 80 & 380 \\
Advanced fireplaces - wood & 95 & 95 \\
Advanced stoves - wood & 95 & 95 \\
Pellets stoves - wood & 80 & 29 \\
Boilers - hard coal & 158 & 225 \\
\hline
\end{tabular}


When data are available at national level, data at subdomain level is evaluated using the following eqn:

$$
\mathrm{A}_{\mathrm{i}}=\left(\mathrm{A} * \mathrm{Q}_{\mathrm{d}} / \Sigma_{\mathrm{d}} \mathrm{Q}_{\mathrm{d}}\right) * \mathrm{P}_{\mathrm{i}} / \Sigma_{\mathrm{i}} \mathrm{P}_{\mathrm{i}}
$$

where: $A_{i}$ and $P_{i}$ are the values of the variable $A$ and proxy variable $P$ in the subdomain $i, Q_{d}$ the values of the proxy variable $Q$ in domain $d$, and $A$ the national value of proxy variable $A$.

\section{CARBON FOOTPRINT MODELLING}

ClairCity approach is to evaluate in an integrated way emissions inventory and carbon footprint. Future scenarios will be produced for simultaneous reduction of air pollutants emission and carbon footprint.

Taking into account the general goals of the activities and to delimitate the efforts from other partners in data retrieval, we select an approach, generally referred as scope 2 , taking into account emissions that:

- $\quad$ physically occur within the city/region i.e. from sources located within the city boundary;

- $\quad$ occur from the use of electricity, steam, and/or heating/cooling supplied by grids which may or may not cross city/region boundaries.

As the project is finalized to produce strategies for the cities the carbon footprint evaluation will be conducted following an emission inventory approach similar to the approach followed in the Covenant of Mayors [8] and using both:

- "Standard" emission factors (emissions will be evaluated using methodologies and emission factors from IPCC [9] and specific activity level); the methodology cover all the $\mathrm{CO}_{2}$ emissions that occur due to energy consumption within the territory of the city/region, either directly due to fuel combustion within the city/region or indirectly via fuel combustion associated with electricity and heat/cold usage within their area; the standard emission factors are based on the carbon content of each fuel, like in national greenhouse gas inventories in the context of the UNFCCC and the Kyoto protocol; in the standard approach, the $\mathrm{CO}_{2}$ emissions from the sustainable use of biomass/biofuels, as well as emissions of certified green electricity, are considered to be zero; emission are reported as

o $\mathrm{CO}_{2}$ only emissions, the most important greenhouse gas,

o $\mathrm{CO}_{2}$ equivalent emissions, including calculation of the emissions of $\mathrm{CH}_{4}$ and $\mathrm{N}_{2} \mathrm{O}$ with emission factor from IPCC [9] and reported as $\mathrm{CO}_{2}$ equivalent using the Global Warming Potential (GWP) with 100-year time horizon [10]:

$$
\begin{gathered}
1 \mathrm{Mg} \mathrm{CO}_{2}=1 \mathrm{Mg} \mathrm{CO}_{2} \text {-eq } \\
1 \mathrm{Mg} \mathrm{CH} 4=21 \mathrm{Mg} \mathrm{CO} 2 \text {-eq } \\
1 \mathrm{Mg} \mathrm{N} 2 \mathrm{O}=310 \mathrm{Mg} \mathrm{CO} 2 \text {-eq; }
\end{gathered}
$$

- LCA emission factors, which take into consideration the overall life cycle of the energy carrier; this approach includes not only the emissions of the final combustion, but also all emissions of the supply chain; it includes emissions from exploitation, transport and processing (e.g. refinery) steps in addition to the final combustion; this hence includes also emissions that take place outside the location where the fuel is used; in this approach, the emissions from the use of biomass/biofuels, as well as emissions of certified green electricity, are higher than 
zero; other greenhouse gases than $\mathrm{CO}_{2}$ may play an important role, therefore the LCA approach will report emissions as $\mathrm{CO}_{2}$ equivalent.

The carbon footprint tool calculates emissions detailed by fuels with:

where:

$$
\mathrm{E}_{\mathrm{k}}=\mathrm{C}_{\mathrm{ij}} \mathrm{F}_{\mathrm{ik}} \text {, }
$$

- $\mathrm{C}_{\mathrm{ij}}$ is the consumptions of fuel $\mathrm{i}$ in the territorial unit $\mathrm{j}$

- $\mathrm{F}_{\mathrm{ik}}$ is the emission factor for different carbon footprint indicators $\mathrm{k}$ for fuel $\mathrm{i}$ (expressed in grams per unit of activity);

- $\mathrm{k}$ is the carbon footprint indicator used: $\mathrm{CO}_{2}, \mathrm{CO}_{2 \mathrm{eq}}, \mathrm{CO}_{2 \mathrm{eq}, \mathrm{LCA}}$

In Table 2 the $\mathrm{CO}_{2}$ fuel emission factors used are reported [11]; as a default, for standard emission factors, IPPC [9] values are used, while, for LCA, emission factors given in Covenant of Mayors guidelines, based on JRC European Reference Life Cycle Database, are used [12]. In Table 3 electricity consumptions national emission factors for Bristol [13] and Amsterdam [14] are reported to use for $\mathrm{CO}_{2}$ indirect emissions from electricity consumptions (LCA EFs derived using the same ratio with standard ones as in JRC).

For data evaluation on domains and subdomains the same methodology as for emission inventory is used.

Table 2: $\mathrm{CO}_{2}$ Emission Factors [EF].

\begin{tabular}{lccc}
\hline \multicolumn{1}{c}{ Fuel } & $\begin{array}{c}\text { Standard EF } \\
{[\mathrm{Mg} \mathrm{CO} 2 /} \\
\text { MWh }]\end{array}$ & $\begin{array}{c}\text { Standard EF } \\
{[\mathrm{Mg} \text { CO2eq/ }} \\
\text { MWh }]\end{array}$ & $\begin{array}{c}\text { LCA EF } \\
{[\mathrm{Mg} \text { CO2-eq/ }} \\
\text { MWh }]\end{array}$ \\
\hline Motor gasoline & 0.249 & 0.250 & 0.299 \\
Gas oil, diesel & 0.267 & 0.268 & 0.305 \\
Residual fuel oil & 0.279 & 0.279 & 0.310 \\
Anthracite & 0.354 & 0.356 & 0.393 \\
Other bituminous coal & 0.341 & 0.342 & 0.380 \\
Sub-bituminous coal & 0.346 & 0.348 & 0.385 \\
Lignite & 0.364 & 0.365 & 0.375 \\
Natural gas & 0.202 & 0.202 & 0.237 \\
Municipal wastes (non-biomass) & 0.330 & 0.337 & 0.330 \\
Municipal wastes (biomass) $_{\text {Wood }^{1}}$ & 0 & 0.007 & 0.106 \\
Plant oil $^{1}$ & $0-0.403$ & $0.007-0.410$ & $0.017-0.416$ \\
Biodiesel $^{1}$ & $0-0.287$ & $0.001-0.302$ & $0.182-0.484$ \\
\hline
\end{tabular}

${ }^{1}$ Lower value if fuel meets carbon neutrality criteria, higher otherwise.

Table 3: $\mathrm{CO}_{2}$ Electricity National Emission Factors.

\begin{tabular}{lccc}
\hline \multicolumn{1}{c}{ Fuel } & $\begin{array}{c}\text { Standard Emission } \\
\text { Factors }\end{array}$ & $\begin{array}{c}\text { Standard Emission } \\
\text { Factors }\end{array}$ & $\begin{array}{c}\text { LCA Emission } \\
\text { Factors }\end{array}$ \\
& {$[\mathrm{Mg} \mathrm{CO} / \mathrm{MWh}]$} & {$[\mathrm{Mg} \mathrm{CO} 2 \mathrm{eq} / \mathrm{MWh}]$} & {$[\mathrm{Mg} \mathrm{CO} 2-\mathrm{eq} / \mathrm{MWh}]$} \\
\hline Bristol (UK) & 0.4585 & 0.46219 & 0.5224 \\
Amsterdam (NL) & 0.53 & 0.53 & 0.60 \\
\hline
\end{tabular}




\section{BRISTOL AND AMSTERDAM BASELINE SCENARIO CASE STUDIES}

\subsection{Data sources and methodologies}

The following reference data and methodologies are used for Bristol case study:

- Industrial sources: Emissions from NAEI large point sources [15];

- Energy consumptions

o Industrial sector: data at MSOA for natural gas and LA level for electricity and other fuel [16]; total consumptions allocated to sectors using national figures [16]; data at LSOA obtained using employees [17];

o Residential sector: data at LSOA level for electricity and natural gas and at LA level for wood, LPG, gasoil, coal allocated to LSOA with households not connected to the gas network (where consumptions are available only as aggregation of fuels, shares from national statistics are used) [16]; Domestic wood technologies split obtained from a national domestic wood use survey [18];

o Service sector: data at MSOA level for electricity and natural gas and at LA level for LPG, gasoil, coal, total consumptions allocated to sectors using national figures [16]; data at LSOA obtained using employees [17];

o Transport sector: data from ClairCity project (unpublished).

The following reference data and methodologies are used for Amsterdam case study:

- Industrial sources: Emissions from Emissieregistratie large point sources [19];

- Energy consumptions

o Industrial sector: data at national level allocated to buurt using industry companies number [20];

o Residential sector: data at buurt level for electricity and natural gas [20]; data at gemeente level for wood [21] and at national level for LPG and gasoil allocated to buurt with population [20]; domestic wood technologies split obtained from a national survey [22] and EMEP emission inventory data for Netherland;

o Service sector: data at gemeente level for electricity and natural gas [21] and at national level for wood, LPG and gasoil, allocated to sectors using national figures [20]; data at buurt obtained using industry companies number [20];

o Transport sector: data from ClairCity project (unpublished).

\subsection{Territorial domains}

For air pollutants emissions inventories air quality modelling domains are used (box areas in Figs 2-4) with data for LSOA (Bristol) and buurt (Amsterdam) belonging to the domain.

\section{AIR POLLUTANTS EMISSIONS}

Some examples of results are reported for emissions by LSOA for Bristol city $\left(\mathrm{PM}_{10}\right.$ emissions from solid biomass on Fig. 2 and industry $\mathrm{NO}_{\mathrm{x}}$ emissions on Fig. 3) and by buurt for Amsterdam city (residential and commercial $\mathrm{NO}_{\mathrm{x}}$ emissions on Fig. 4).

\subsection{Carbon footprint}

In Table 4 carbon footprint by fuel is reported for Bristol expressed as $\mathrm{CO}_{2}, \mathrm{CO}_{2}$ equivalent and $\mathrm{CO}_{2}$ equivalent on Life Cycle while, in Fig. 5, carbon footprint expressed as $\mathrm{CO}_{2}$ equivalent on Life Cycle is reported by fuel and sector. 


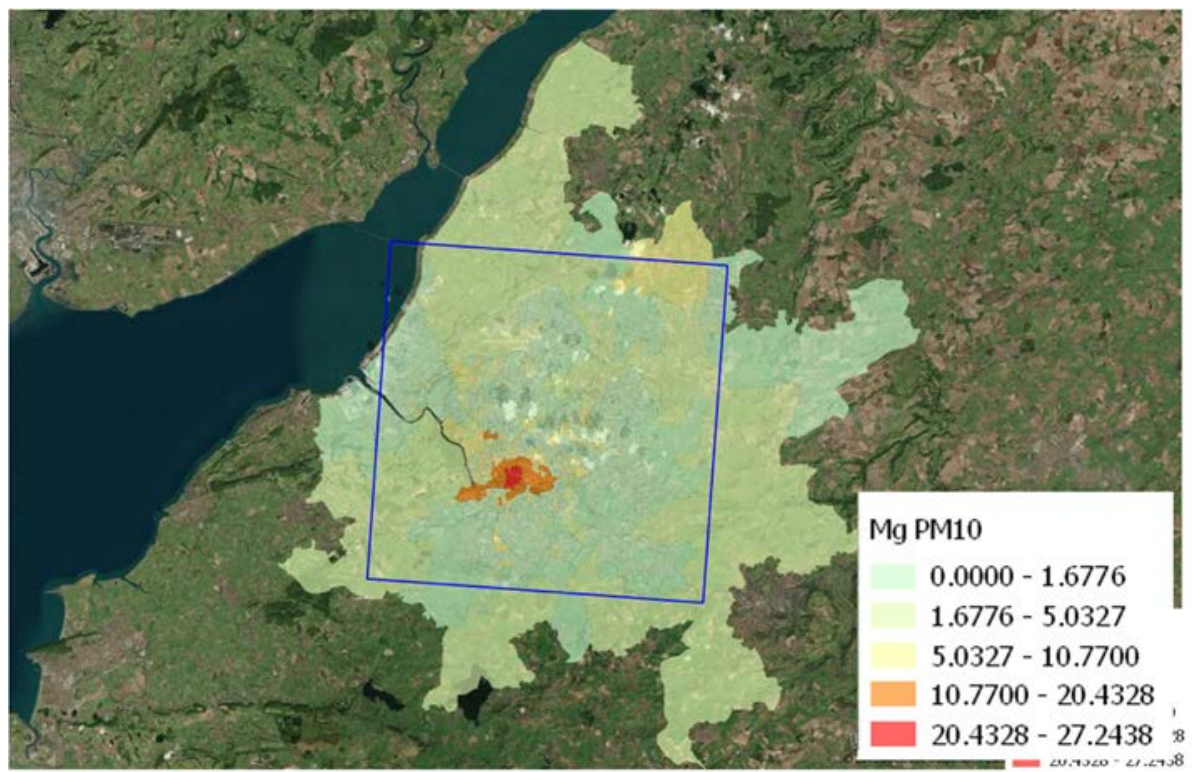

Figure 2: Bristol LSOA residential and commercial $\mathrm{PM}_{10}$ emissions from solid biomass combustion.

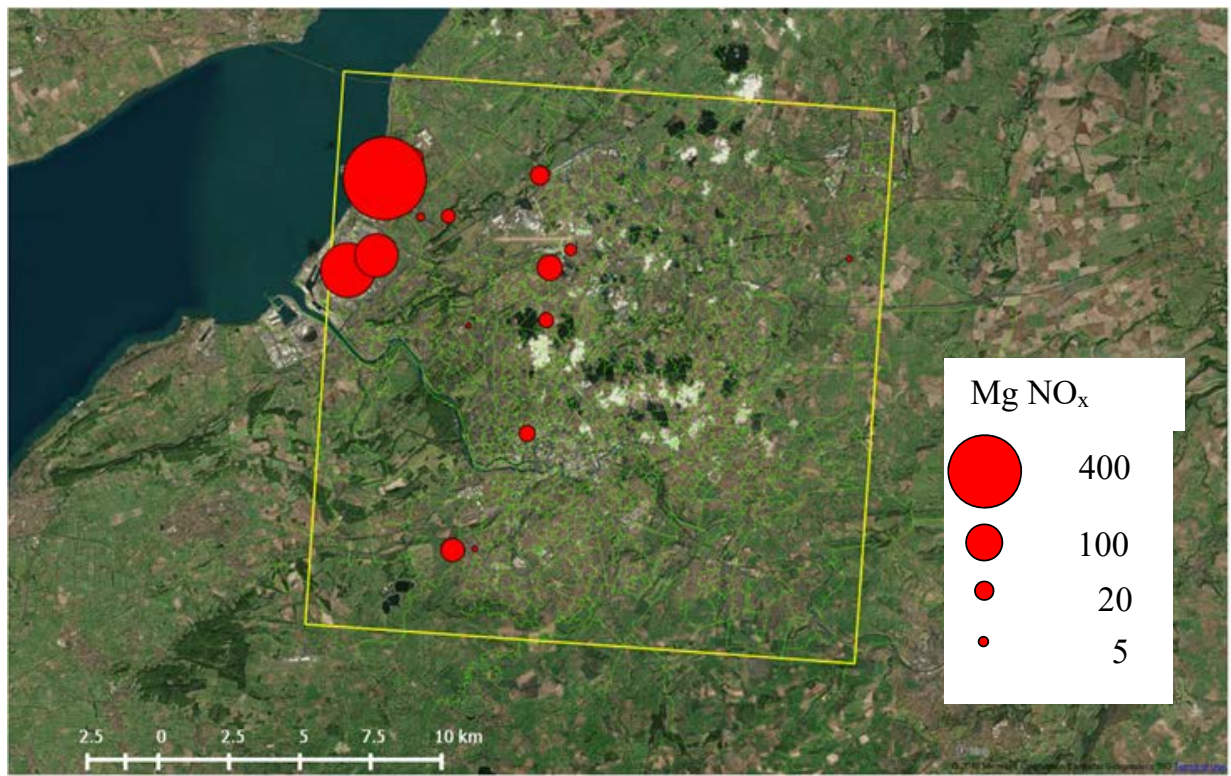

Figure 3: Bristol industry $\mathrm{NO}_{\mathrm{x}}$ emissions. 


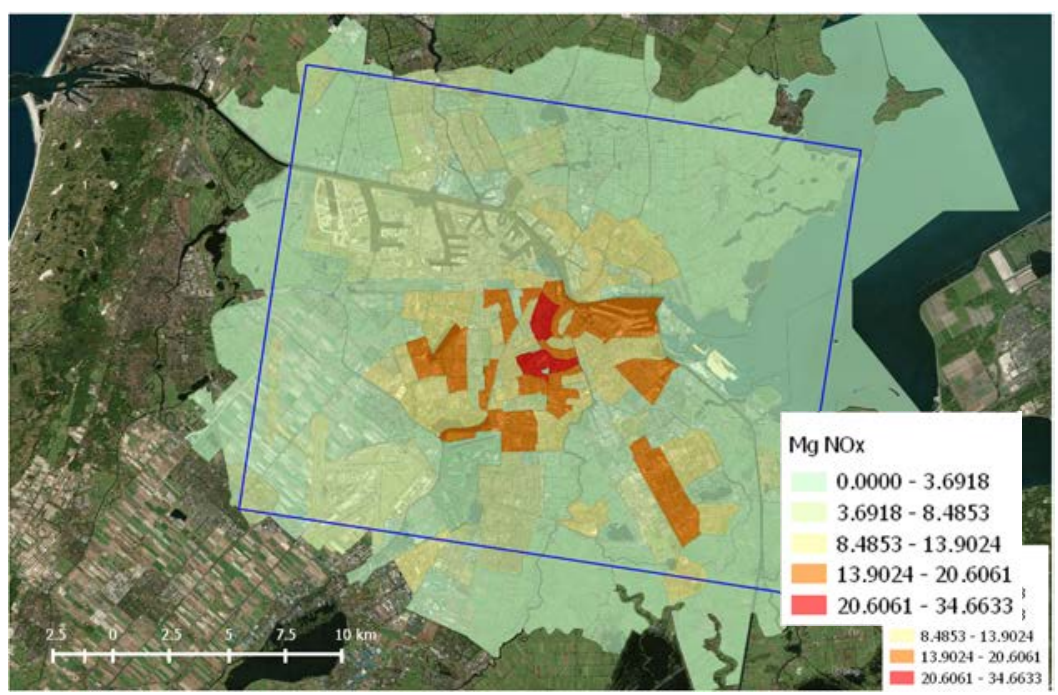

Figure 4: Amsterdam buurt residential and commercial $\mathrm{NO}_{\mathrm{x}}$ all sectors and fuels emissions.

Table 4: Bristol carbon footprint by fuel (Mg).

\begin{tabular}{|c|c|c|c|}
\hline Energy vector & $\mathrm{CO}_{2}$ & $\mathrm{CO}_{2 \mathrm{eq}}$ & $\mathrm{CO}_{2 \mathrm{eq}, \mathrm{LCA}}$ \\
\hline Biomass & - & 2.711 & 6.706 \\
\hline Gasoil/diesel & 210.902 & 211.471 & 241.599 \\
\hline Gasoline & 160.192 & 160.655 & 201.860 \\
\hline Hard Coal & 9.037 & 9.093 & 9.479 \\
\hline LPG & 3.678 & 3.678 & 4.552 \\
\hline Natural gas & 544.097 & 544.097 & 646.903 \\
\hline Electricity & 953.299 & 956.630 & 1.089 .865 \\
\hline Total & 1.881 .204 & 1.888 .334 & 2.200 .964 \\
\hline \multirow{9}{*}{$\begin{array}{r}1.000 .000 \\
900.000 \\
800.000 \\
700.000 \\
600.000 \\
500.000 \\
400.000 \\
300.000 \\
200.000 \\
100.000\end{array}$} & & & \multirow{8}{*}{$\begin{array}{l}\text { Electricity } \\
\text { Natural gas } \\
\text { LPG } \\
\text { - Hard Coal } \\
\text { Gasoline } \\
\text { Gasoil/diese } \\
\text { Biomass }\end{array}$} \\
\hline & & & \\
\hline & & & \\
\hline & & & \\
\hline & & & \\
\hline & & & \\
\hline & & & \\
\hline & & & \\
\hline & Residential & Services & \\
\hline
\end{tabular}

Figure 5: Bristol carbon footprint ( $\mathrm{Mg} \mathrm{CO}_{2}$ equivalent on Life Cycle). 


\subsubsection{Amsterdam city}

In Table 5 carbon footprint by fuel is reported for Amsterdam expressed as $\mathrm{CO}_{2}, \mathrm{CO}_{2}$ equivalent and $\mathrm{CO}_{2}$ equivalent on Life Cycle. In Fig. 6 carbon footprint expressed as $\mathrm{CO}_{2}$ equivalent on Life Cycle is reported by fuel and sector while in Fig. 7 total carbon footprint is showed by buurt.

Table 5: Amsterdam carbon footprint by fuel (Mg).

\begin{tabular}{lccc}
\hline Energy vector & $\mathrm{CO}_{2}$ & $\mathrm{CO}_{2 \mathrm{eq}}$ & $\mathrm{CO}_{2 \mathrm{eq}, \mathrm{LCA}}$ \\
\hline Biomass & - & 1.797 & 4.445 \\
Gasoil/diesel & 356.483 & 357.444 & 408.370 \\
Gasoline & 559.240 & 560.856 & 704.707 \\
Hard Coal & 62.569 & 62.959 & 65.629 \\
LPG & 18.594 & 18.594 & 23.014 \\
Natural gas & 1.586 .120 & 1.586 .120 & 1.885 .815 \\
Electricity & 2.205 .778 & 2.209 .479 & 2.498 .155 \\
Total & 4.788 .783 & 4.797 .249 & 5.590 .134 \\
\hline
\end{tabular}

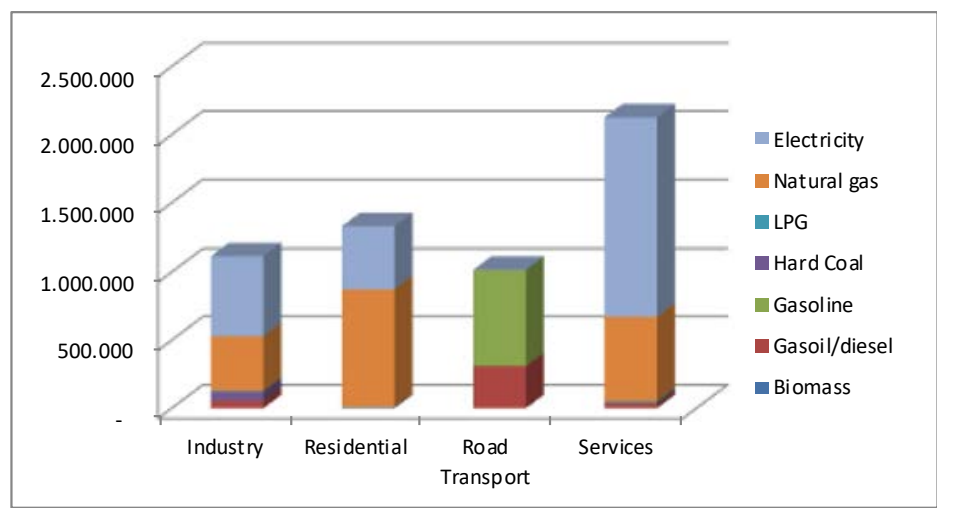

Figure 6: Amsterdam carbon footprint $\left(\mathrm{Mg} \mathrm{CO}_{2}\right.$ equivalent on Life Cycle).

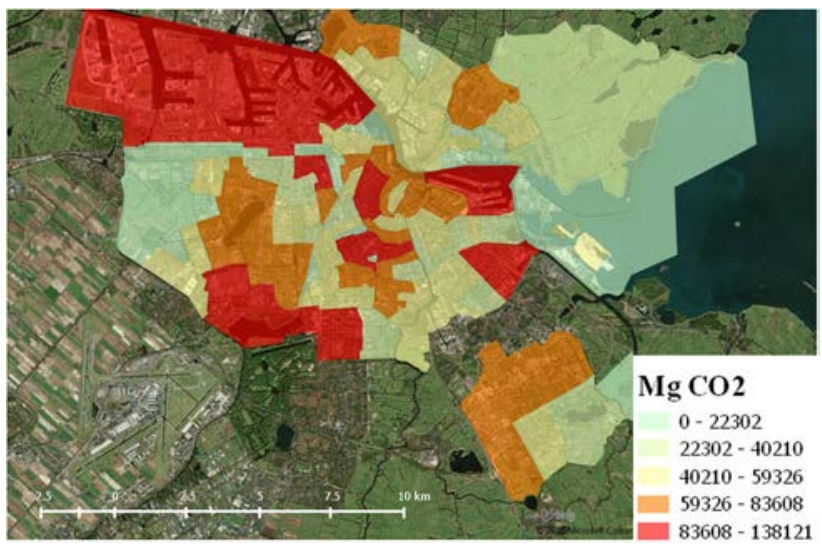

Figure 7: Amsterdam buurt carbon footprint - all sectors. 


\section{CONCLUSIONS}

For a long time, policies aimed at reducing greenhouse gases emissions and those aimed at improving air quality have been indifferent to one another if not in contradiction. Inside ClairCity project a complete innovative set of tools for the integrated evaluation of air pollution and carbon footprint at city level was designed and developed.

The paper reports methodologies and case studies for integrated quantification of air pollutants emissions and carbon footprint at city level in the frame of Horizon 2020 Project ClairCity. The methodologies and results obtained will be used in future as an input for air quality, exposure and impact models as well as the tools used in city engagement: the game and app. The data will furthermore represent the base case for future scenario evaluation.

\section{ACKNOWLEDGEMENT}

The study was carried out in the frame of ClairCity project. The project has received funding from the European Union's Horizon 2020 research and innovation programme under grant agreement No 689289.

\section{REFERENCES}

[1] European Commission, ClairCity, Community Research and Development Information Service (CORDIS). https://cordis.europa.eu/ project/rcn/202636_en.html. Accessed on: 19 May 2018.

[2] European Commission, Horizon 2020 - The Framework Programme for Research and Innovation, COM/2011/0808 final.

[3] ClairCity Technical Summary, 2016.

[4] EU Science Hub, Air quality and greenhouse gases. https://ec.europa.eu/jrc/en/ research-topic/air-quality. Accessed on: Jun. 2018.

[5] The Covenant of Mayors for Climate \& Energy, Commitment document. https://www.covenantofmayors.eu/index.php?option $=$ com_attachments\&task $=$ downl oad\&id=11. Accessed on: Jun. 2018.

[6] European Pollutant Release and Transfer Register (E-PRTR). http://prtr.ec. europa.eu/\#/facilitylevels.

[7] EMEP/EEA, Air pollutant emission inventory guidebook 2016, EEA European Environment Agency, EEA Report No 21/2016, 2016.

[8] Covenant of Mayors, How to develop a Sustainable Energy Action Plan (SEAP) Guidebook Part II, Baseline emissions inventory, 2010.

[9] IPCC, 2006 IPCC Guidelines for National Greenhouse Gas Inventories, Volume 2: Energy, 2006.

[10] IPCC, Contribution of Working Group I to the Second Assessment of the Intergovernmental Panel on Climate Change, 1995.

[11] JRC, Covenant of Mayors for Climate and Energy: Default emission factors for local emission inventories, 2017.

[12] European Reference Life Cycle Database (ELCD) Release 3.2. LCA data sets of key energy carriers, materials, waste and transport services of European scope, 2015.

[13] UK Government conversion factors for Company Reporting.

[14] CBS, Rendementen en CO2-emissie elektriciteitsproductie, 2015.

[15] UK Department for Environment Food \& Rural Affairs, Emissions from NAEI large point sources. http://naei.beis.gov.uk/data/map-large-source. Accessed on: Feb. 2018.

[16] UK Department for Business, Energy \& Industrial Strategy. https://www.gov.uk/ government/. Accessed on: Feb. 2018. 
[17] UK Office for National Statistics. https://www.nomisweb.co.uk/census/2011/. Accessed on: Feb. 2018.

[18] UK Department for Business, Energy \& Industrial Strategy, Summary Results of the Domestic Wood Use Survey. Accessed on: Mar. 2016.

[19] Emissieregistratie. https://emissieregistratie.nl. Accessed on: Feb. 2018.

[20] CBS. https://www.cbs.nl/. Accessed on: Feb. 2018.

[21] RIVM, Klimaatmonitor. https://klimaatmonitor.databank.nl/dashboard/. Accessed on: Feb. 2018.

[22] CBS, Houtverbruik bij huishouden (Wood combustion at household), 2010. 